\title{
Gilles Deleuze, Clínico da ATIVIDAde filosófica: PARADOXO DO FILÓSOFO TRABALHADOR
}

\author{
Maria Elizabeth Barros de Barros $\star$ \\ Jésio Zamboni $\star \star$
}

\begin{abstract}
RESUMO
Propõe-se abordar Gilles Deleuze (1925-1995) como filósofo trabalhador, operário dos conceitos. Afirma-se a filosofia como atividade produtiva no contexto capitalista, o que implica a militância do filósofo. Esta luta se faz pela análise da atividade filosófica, como meio de interferência nos processos de produção social, acompanhada pela clínica do trabalho filosófico, como desvio desenvolvido a partir das rupturas analíticas. Discute-se a composição do coletivo de trabalho e a sustentação do gênero de atividade em filosofia por Deleuze. A intercessão com a atividade docente se coloca como crucial. Apresentam-se situações concretas tratadas por Deleuze em sua filosofia: droga, literatura, loucura.
\end{abstract}

Palavras-chave: Gilles Deleuze; filosofia da diferença; clínica da atividade.

\section{Gilles Deleuze, Clinician of Philosophical} ACTIVITY: PARADOX OF A WORKER PHILOSOPHER

\begin{abstract}
Gilles Deleuze (1925-1995) is approached as worker philosopher, a builder of concepts. Philosophy is defined as a productive activity in the capitalist context, which implies the militancy of the philosopher. This struggle takes place by analyzing the philosophical activity as a means of interference in production processes followed by the clinic of philosophical work, a departure developed out of the analytic ruptures. It discusses the composition of the collective of work and the maintenance of the genre of activity in philosophy by Deleuze. The intercession with the teaching activity appears crucial. Specific situations addressed by Deleuze in his philosophy are treated: drugs, literature, madness.
\end{abstract}

Keywords: Gilles Deleuze; philosophy of difference; clinic of activity.

^ Psicóloga. Mestrado em Psicologia Escolar pela Universidade Gama Filho (1980). Doutorado em Educação pela Universidade Federal do Rio de Janeiro (1995) e pós- doutorado em Saúde Pública pela ENSP/Fiocruz (2001).

E-mail: betebarros@uol.com.br

$\star \star$ Graduação em Psicologia pela Universidade Federal do Espírito Santo (UFES). Mestrado em Psicologia Institucional (UFES), linha de pesquisa: Clínica e Subjetividade. Doutorando em Educação (UFES).

E-mail: jesiozamboni@gmail.com 


\section{UM CLÍNICO DA ATIVIDADE FILOSÓFICA}

Em tensionamentos entre a produção constelacionada em clínica da atividade e a esquizoanálise em suas incidências como uma filosofia da diferença, encontramos - ou antes, inventamos - a figura de um clínico da atividade em meio aos filósofos. Seu nome: Gilles Deleuze (1925-1995). Não se trata de um clínico da atividade profissionalizado, empunhando as ferramentas próprias a essa clínica do trabalho tal qual Clot e seus companheiros desenvolvem como clínica da atividade.

A clínica da atividade é uma corrente das clínicas do trabalho (LHUILIER, 2011) que busca, pela intervenção no desenvolvimento da atividade dos trabalhadores, ampliar o poder de agir do coletivo de trabalho sobre a organização de trabalho (CLOT, 2006; 2010b), possibilitando transformá-la em função da imanência dos processos produtivos. Trata-se de um dispositivo teórico-técnico que visa desenvolver a psicologia do trabalho pela experiência dos próprios trabalhadores. Para tal, irá dispor-se à invenção de uma série de dispositivos de análise coletiva do trabalho.

A atividade analítica, entretanto, não é privilégio dos dispositivos desenvolvidos por cientistas ou filósofos profissionais. Em vez de proprietários da análise, esses sujeitos ocupam antes a função de aprimorar e desenvolver instrumentos analíticos. É nesse sentido que evocaremos ferramentas da clínica da atividade, constituindo uma ciência psicológica do trabalho, ${ }^{1}$ para abordar a análise e a clínica da atividade filosófica desenvolvida por Deleuze com seus instrumentos próprios, os conceitos, em filosofia da diferença.

Inventar em Deleuze um clínico da atividade pode ser uma mera decalcomania, ou seja, uma sobreposição de um modelo clínico ao percurso analítico singular desenvolvido pelo filósofo. Isso se produziria em função de uma comparação ou rebatimento de investimentos que temos feito em análises no mundo do trabalho, via consideração da atividade produtiva e da análise desejante no campo social, tratando-as como propriedades constituídas, como domínios de saberes demarcados, cercados e fechados sobre si mesmos. Traçando comparações, similitudes e desigualdades, deixaríamos tranquilas ambas as abordagens da produção social, a esquizoanálise e a clínica da atividade, impedindo nossa instalagem em seus processos constituintes.

Nesse sentido, Gilles Deleuze não é clínico nem analista da atividade por encaixar-se num modelo que se pode supor advindo da clínica da atividade. As análises são as rupturas e desvios que Deleuze desenvolve na atividade filosófica e a clínica são as cartografias e os traçados que se fazem acompanhando essas estilizações pela atividade, por vezes contra ela, para desenvolvê-la. ${ }^{2}$

Desejamos criar um plano comum, uma intercessão ${ }^{3}$ de uma por outra, entre esquizoanálise e clínica da atividade, em cortes e conexões, para que ambas as máquinas de análise social se perturbem mutuamente, para que nos levem a desenvolver a clínica da atividade como produção desejante no campo social. Trata-se de expandir a potência analítica da clínica do trabalho no que ensaiamos como esquizoanálise da atividade. 
Tem-se feito diversos esforços, em trabalhos distintos, por traçar uma intercessão entre a produção deleuzeana em filosofia da diferença e a produção, disparada por Yves Clot, em clínica da atividade (MAIA, 2006; TEIXEIRA; BARROS, 2009; AMADOR, 2009; LOUZADA, 2009; BARROS; PINHEIRO; ZAMBONI, 2010). Estes, entre outros trabalhos, nos apoiam nessa empreitada. São obras que, ao arranjarem-se pelos mais diversos procedimentos, inventam zonas de indiscernibilidade entre a clínica da atividade e a filosofia da diferença. Enfrenta-se nessas intercessões o desafio de não subsumir uma produção a outra. Procura-se fazer coexistirem diferenciações pelo desenvolvimento das controvérsias, por perturbações mútuas, promovendo invenções desde os instrumentos que ambas as maquinarias nos legam. Já que dois numa conversa já são uma multidão, já nem dá pra imaginar esse monte de gente, coisas e relações: resta atravessá-lo, habitá-lo, produzi-lo junto.

Não se trata, então, de um mero caso de reconhecimento, mas de estilização. Não nos propomos a colocar Gilles num tribunal para avaliar se ele merece ou não o título de clínico da atividade. Gilles Deleuze é analista da atividade filosófica, mas também clínico, por acompanhar os processos que envolvem as análises, marcando suas variações de modo a dispará-las a partir de pontos de ruptura.

\section{UM OPERÁRIO DOS CONCEITOS}

Deleuze é um nome em filosofia como uma "máscara de operador" (DELEUZE, 2006a, p. 325) que não designa mais um eu, uma identidade, uma pessoa, mas variações intensivas, disjunções inclusivas, efeitos de transformação. ${ }^{4}$ O próprio nome de Deleuze designa uma multiplicidade de outros nomes que por meio dele falam, e por meio dos quais ele pode falar. Trata-se de um signo-limite, uma posição de borda, pelo qual a filosofia abre-se à estilização na pessoa de Deleuze. Existe, como em outros domínios do conhecimento - por exemplo, o efeito-kelvin ou efeito-joule em termodinâmica -, um efeito-deleuze que percorre a máquina filosófica e a desenvolve, não num sentido progressivo, mas involutivo, por elevações de potência, num movimento de repetição diferenciante, num eterno retorno da diferença (DELEUZE, 1976; 1980; 2006b).

A cada vez que Deleuze retoma alguma produção no campo da filosofia, mas também das artes e das ciências, o produto do seu trabalho sobre, ou antes, acerca de outro trabalho assume um tom de criação pela atividade de construção de conceitos, própria ao filósofo que se propõe a essas conversações em função do seu ofício. Configuram-se novos arranjos de saber, constituem-se novas paisagens de conhecimento, tornando-se, por vezes, irreconhecíveis os traços da obra (re)trabalhada. Deleuze agita as linhas duras recodificadas que tornam seus interlocutores facilmente reconhecíveis e classificáveis. Pretende, a cada vez que retoma um trabalho, sustentar-lhe as forças que o constituem, inviabilizando que interpretações sobre eles se tornem definitivas, conclusivas, taxativas. A respeito de obras filosóficas, e também de outros gêneros profissionais, Deleuze se propõe a trabalhar, em seus entornos, afirmando a abertura da obra, seu caráter infinito pelo pensamento, ainda que acabado. 
O término de uma obra é tomado por Deleuze como um terminal, onde se podem iniciar outras viagens, onde os mais diversos trajetos se entrecruzam. Afirmam-se nos trabalhos de Deleuze as forças de produção guardadas em cada obra, seus múltiplos sentidos em jogo. A multiplicidade que compõe cada trabalho abordado por Deleuze é considerada como seu fora, ${ }^{5}$ seu meio de existência, sua via sempre aberta a bifurcações - nem universo indiferenciado, nem contexto determinado. $\mathrm{O}$ fora próprio à obra interessa a Deleuze como o plano das forças de composição da materialidade trabalhada.

Gilles Deleuze trabalha a filosofia como uma máquina de produzir conceitos (DELEUZE; GUATTARI, 1997). É um trabalhador, um operário, da produção conceitual, filosófica. Ele habita o gênero profissional filósofo em seu limite, na consideração do fora na filosofia, ou seja, daquilo que não é filosofia, mas que a compõe por intercessões, jogando com as forças que permeiam, atravessam e constituem-na. Esse limite, esse fora, privilegiado por Deleuze, é a perturbação, o deslocamento, a fragmentação interna ${ }^{6}$ que marca a emergência de variantes em heterogeneizações no gênero de trabalho, tal como o define Yves Clot $(2006 ; 2010)$.

Eles [gêneros de atividades] são os antecedentes ou os pressupostos sociais da atividade em curso, uma memória transpessoal e coletiva que confere seu conteúdo à atividade pessoal em situação. [...] Dado a recriar na ação, essas convenções da ação para agir são, ao mesmo tempo restrições e recursos. Elas têm o caráter de um premeditado social em movimento [...] Mas, eis que o gênero não é amorfo: porque ele é o meio para agir com eficácia, sua estabilidade é sempre transitória. Se se tratasse de uma norma ou de um simples sistema de filiação, ele seria, em sua natureza de ser, intangível; mas, em vez de ser apenas organização, ele é igualmente instrumento, no sentido atribuído a este termo por Rabardel $(1995,1999)$, constantemente submetido à prova do real; não somente obrigação a respeitar, mas também recurso a renovar e método a ajustar. (CLOT, 2006, p. 123-125)

A matéria filosófica operada por Deleuze é composição genérica constituindo-se por meio de variações intensivas engendrando heterogêneses no plano conceitual, fazendo da filosofia um campo aberto à criação, à estilização. As criações deleuzeanas desenvolvem a filosofia pelo movimento que possibilita a deriva de intensidades dos conceitos, através de outros campos, como a política, a arte, a ciência, o trabalho. Essa estilização, contudo, não funciona anulando o gênero filosófico, "mas graças a ele usando seus recursos, suas variantes, em outros termos, por meio do seu desenvolvimento, impelindo-o a renovar-se" (CLOT, 2006, p. 41).

Deleuze é analista e clínico da atividade filosófica, sem trabalhar com o conceito de atividade. Isso nos coloca a dimensão da clínica da atividade para além de sua especialidade no campo da psicologia do trabalho, não se opondo ela, mas instigando-a a desenvolver-se, produzindo um fora na clínica da atividade que potencializa o plano de criação no desenvolvimento dessa clínica. 
Deleuze aprende com Friedrich Nietzsche (apud DELEUZE; GUATTARI, 1997), dentre outros, a ser um operário da filosofia: "os filósofos não devem mais contentar-se em aceitar os conceitos que lhes são dados, para somente limpá-los e fazê-los reluzir, mas é necessário que eles comecem a fabricá-los, criá-los, afirmá-los, persuadindo os homens a utilizá-los" (p. 13-14). Deleuze assume, então, trabalhar sempre com os conceitos como ferramentas, tomadas não como dadas, prontas, acabadas de uma vez por todas, a serem melhor descobertas, mas sempre lançadas, a cada vez, em movimentos de produção, de criação, de apropriação, em instrumentos situados, a serem inventados continuamente. Esse princípio ético-político é comum ao assumido por Yves Schwartz (2004) - propositor da ergologia, uma abordagem filosófica e prática do trabalho pelo conceito de atividade, e orientador de tese de Yves Clot -, para quem todo conceito se modifica sempre a cada vez que é usado nos arranjos situacionais que nunca são os mesmos, afirmando assim o devir conceitual.

É nesse sentido de assunção de um certo modo de trabalhar em filosofia que Deleuze não aceita qualquer prescrição para o seu ofício, mas interfere radicalmente na organização do trabalho filosófico. Diante de tarefas tais como ser um comentador dos filósofos consagrados, ser um contemplador das entidades transcendentes - a verdade, o bem, o belo, dentre outras -, ser o sujeito da reflexão de tudo e qualquer coisa, ser o articulador e substrato da comunicação geral, Deleuze produz uma das mais potentes lutas contra essas maneiras de trabalhar que emergem no campo filosófico. Uma luta que não cai no mero protesto ou recusa, mas uma luta pela filosofia que a afirma como atividade produtora.

Deleuze via nessas tarefas, repudiadas e consideradas por ele medíocres, não a superioridade da filosofia em relação aos outros domínios da produção social, mas exatamente, obstáculos que derivavam da confusão do filósofo com o sábio ascético que marcam o surgimento desse profissional na Antiga Grécia. "A contemplação, a reflexão, a comunicação não são disciplinas, mas máquinas de constituir Universais em todas as disciplinas. [...] O primeiro princípio da filosofia é que os Universais não explicam nada, eles próprios devem ser explicados" (DELEUZE; GUATTARI, 1997, p. 15). Deleuze se engaja, portanto, na orientação ético-estético-política de combater os absolutismos, os totalitarismos, a partir da sua própria atividade produtiva, do seu próprio meio profissional, a filosofia. Deleuze não acredita numa militância que não seja produtiva, em lutas que não invistam a criação de mundos, de instrumentos para construí-los, em modos de vida potentes e afirmativos.

\section{A PRODUTIVIDAdE COMO MILITÂNCIA EM FILOSOFIA}

Deleuze é um militante da multiplicidade pelo rompimento com os militantismos cujo centro de atividade é o protesto e a conscientização por exclusão de outros modos de luta social. Nem bom senso, nem senso comum, a aposta de Deleuze é no contrassenso. Aposta política pela sua própria atividade profissional, pela produção de outros modos de pensar, por outros modos de viver. Nesse sentido, construir conceitos torna-se crucial, pois eles tornam- 
se instrumentos na construção de mundos. Deleuze afirma-se, em filosofia, como profissional da produção de conceitos, militante situado no trabalho, inventor do ofício de(sde) sua própria atividade.

Por essa via, afirma-se o trabalho do filósofo como atividade política, rejeitando a dicotomia disciplinar que separa e antagoniza atividade produtiva e questões sociais, trabalho e luta, criação e vida. Desse modo, rejeita-se a filosofia como atividade transcendente às relações sociais contemporâneas. A filosofia, para Deleuze, é atividade concreta situada nos modos de produção em jogo, perpassando as problemáticas do capital, dentre outras. É por esse movimento duplo, afirmar a filosofia como política e como trabalho, que Deleuze constrói a filosofia como atividade situada.?

Nesse sentido, Deleuze está muito próximo de Yves Clot (2010a), que investe a necessidade de lutar pela qualidade do trabalho, como uma orientação ético-estético-política fundamental do clínico da atividade. Clot (2006, p. 8) defende arduamente o trabalho, acredita que esse plano de atividade é fundamental para o desenvolvimento da autonomia em coletivos, considerando-a "a atividade mais transpessoal possível", por ser o eixo crucial da produção em seus paradoxos tal como nos colocamos na história. Nesse sentido, Clot e Deleuze estão num plano comum de lutas: o da produção de mundos. Com isso, não há de se deixarem de lado as nuances, confundindo o comum com o semelhante. Pelo contrário, no ponto de vista de ambos, é crucial afirmar as controvérsias, as disjunções de modo inclusivo, a criação de uma comunidade que não seja a da homogeneização, mas a da produção de diferenças impelidas a desenvolverem-se pelos tensionamentos mútuos, comunidade de criadores de mundos, de afirmadores da vida em sua potência de diferir. Deleuze e Clot lutam pelo desenvolvimento dos diversos gêneros de atividade produtiva em suas intercessões, cada um a seu modo, afirmando as diferenças entre si pela constituição de múltiplas relações transversais desde as situações laborais próprias.

A partir daí, todo o empenho que se toma para impedir as intercessões da filosofia com os artistas e os trabalhadores, principalmente, (dis)juntando-os exclusivamente, tornando-os quase que completamente estranhos um ao outro, é um dos grandes entraves que a filosofia constituiu para si, em sua história, em seu meio profissional. Configuram-se, por esse impedimento, contradições que se tornam, por assumir uma forma com aparências de eternidade, por cair numa estruturação bloqueadora dos movimentos de criação, um impasse a desmontar em paradoxos. Gilles Deleuze é um filósofo que não cessa de questionar essas disjunções exclusivas entre filosofia, arte e trabalho.

Deleuze habitava a oficina de conceitos, operando com esses instrumentos longas fabricações que duravam em tempos e lugares diversos. Um trabalhador que amava seu ofício, de um rigor e uma dedicação admirável. Bom senso operário? A nosso ver, contrassenso ao rendimento de capital, pois trabalhava furtando-se à expropriação dos sentidos, das ferramentas conceituais, das máquinas de guerra ${ }^{8}$ filosóficas, dentre outras, pelos conjuntos militares disciplinados em empresas no contemporâneo. E o desmontar 
de uma empresa da filosofia, empresa que se faz pelo desencantamento da metafísica, que Deleuze engaja como tarefa negativa enlaçada à tarefa positiva de um construtor conceitual, de um mecânico das máquinas desejantes ${ }^{9}$ e sociais produtoras de conceitos. Uma desmontagem incessante que afirma as lutas cotidianas no meio de trabalho filosófico. Contrassenso operário.

Deleuze situa sua atividade para não cair na equivalência geral do capital sobre as produções singulares no campo social; procura afirmar as singularizações no trabalho filosófico, pela retomada de seus movimentos criativos. Estabelecendo relações com outras diversas atividades, busca sustentar essas diferenciações. Analista da atividade filosófica por intercessão das atividades do cinema, da pintura, da literatura - Deleuze é clínico por atravessar essa análise marcando os sintomas doentios na filosofia, seus pontos de bloqueio, de um esvaziamento pelo discurso do "fim da metafísica", que não deixa de lembrar os discursos de "fim do trabalho", no pós Segunda Grande Guerra Mundial. Yves Clot (2006) também rejeita radicalmente essa abordagem, afirmando a centralidade do trabalho nos processos de produção da subjetividade no contemporâneo. Por sua vez, Deleuze trata esses sintomas que atravessam o corpo social por meio do próprio trabalho filosófico no que eles afetam essa atividade; situa os problemas abstratos, que percorrem o corpo social, para trabalhá-los em seu meio produtivo. Pode-se assim afirmar a filosofia como "uma ocupação bem definida, uma atividade precisa" (CLOT, 2006, p. 15), desviando-a das ilusões de domínio ou rebaixamento em relação a outros meios de produção.

\section{Rupturas E AlianÇAS PElA COMPOSIÇÃo DE UM COLETIVO DE TRABALHO EM FILOSOFIA}

Deleuze está sempre em luta para escapar das estruturações que obstruem a produção conceitual - os universais da reflexão, da comunicação e da contemplação são seus grandes adversários. Seja num sentido de elevar a filosofia acima de outros tipos de produção, como as artes e as ciências, seja para rebaixá-la por não lhe atribuir uma atividade de produção situável entre estas outras, Deleuze não endossa tais perspectivas. Trata-se de uma recusa à competição, à sobreposição hierárquica, entre as atividades, de uma radical afirmação do meio de trabalho próprio da atividade filosófica pela afirmação da singularidade de outras atividades, afirmando-as sem comparação, por intercessões. Embora considerasse vil o trabalho de denúncia e oposição, por vezes Deleuze assumia tais posições em relação a outros trabalhos para logo retomar sua produção diante daquilo que admirava, do que lhe arrebatava em paixões pelo ofício. E, nesse trabalho, um dos desafios maiores encarados por Deleuze terá sido o problema da história da filosofia.

Sou de uma geração, uma das últimas gerações que foram mais ou menos assassinadas com a história da filosofia. A história da filosofia exerce em filosofia uma função repressora evidente, é o Édipo propriamente filosófico: "você não vai se atrever a falar em seu nome enquanto não tiver 
lido isto e aquilo, e aquilo sobre isto, e isto sobre aquilo". $\mathrm{Na}$ minha geração muitos não escaparam disso, outros sim, inventando seus próprios métodos e novas regras, um novo tom. (DELEUZE, 1992, p. 14)

Pode-se surpreender, então, ao olhar a vasta obra filosófica escrita por Deleuze e se deparar com diversos livros que poderiam ser rapidamente identificadas como obras de história da filosofia, abordagens tipológicas e monumentais de filósofos clássicos. É encarando a história da filosofia, subvertendo-a em seu próprio campo, em vez de abandoná-lo ou menosprezá-lo, como nas produções pós-metafísicas, que Deleuze afirma a filosofia como oficina ou indústria dos conceitos e campo de lutas privilegiado para desmontar os constrangimentos à vida pelo seu próprio trabalho. Deleuze não busca inventar em outro lugar, em alguma transcendência, as armas para lutar contra os entraves em que a filosofia se enredou.

É precisamente nesse sentido que Deleuze é um analista da atividade filosófica. Porque é no próprio chão da fábrica dos conceitos que busca transformar as relações de produção de subjetividade, pela transformação e fortalecimento da atividade de trabalho do filósofo. Deleuze (1976), com Nietzsche, "não acredita nos "grandes acontecimentos" ruidosos, mas na pluralidade silenciosa dos sentidos de cada acontecimento" (p. 3). E é junto com cada filósofo com o qual se alia, em seu universo de produção próprio, pelo trabalho desse sujeito que não abandona o gênero filosófico, que acontece o cuidado e a manutenção do seu ofício, em suas variações intensivas, em suas produções singulares. Desse modo, Deleuze redefine o que é fazer filosofia pelo enfrentamento no campo próprio da história da filosofia, grande máquina de constranger a produção conceitual.

Mas minha principal maneira de me safar nessa época foi concebendo a história da filosofia como uma espécie de enrabada, ou, o que dá no mesmo, de imaculada concepção. Eu me imaginava chegando pelas costas de um autor e lhe fazendo um filho, que seria seu, e no entanto seria monstruoso. Que fosse seu era muito importante, porque o autor precisava efetivamente ter dito tudo aquilo que eu lhe fazia dizer. Mas que o filho fosse monstruoso também representava uma necessidade, porque era preciso passar por toda espécie de descentramentos, deslizes, quebras, emissões secretas que me deram muito prazer (DELEUZE, 1992, p. 14)

Deleuze produz, ao inventar esse procedimento de trabalho em história da filosofia, diversas alianças, estranhas alianças, que se encadeiam umas às outras pelo seu trabalho, entre filósofos que poderiam facilmente ser separados em estantes distintas, e até opostas, em função dos crivos hegemônicos de interpretação. ${ }^{10}$ Essas linhagens se fazem, antes de tudo, por intensidades, por forças que se compartilham, pela afirmação da vida em sua potência de produzir, de diferenciar. As alianças assim firmadas conjuram a conformação de escolas por meio de identificações, de estabelecimentos de conjuntos por meio de traços de similitude. São os múltiplos modos de sustentar os paradoxos conceituais, por vezes tornados contradições 
inelutáveis em filosofia, que Deleuze busca inventariar e aliançar em coletivos de filósofos estranhamente aproximados. Esses profissionais compõem o bando que Deleuze inventa para constituir sua filiação filosófica, como uma herança artificial e uma linhagem intensiva, que afirma a potência da criação, da invenção, do falso.

Essas alianças compõem o plano genérico, composto de variantes assentadas em um meio comum de produção, que Deleuze trabalha, transtornando o campo da filosofia em um plano de invenção. Isso acaba por extrapolar o terreno delimitado da produção filosófica por afirmá-lo, por desenvolvê-lo, por trabalhálo, nos seus contornos, tensionando-os, e não desmanchando-os ou engessandoos. Deleuze opera pelo legado do gênero filosófico como um plano de imanência ${ }^{11}$ para afirmar o movimento incessante de criação em intercessões com outros gêneros de atividade na vida. Dessacralizam-se os aliados e os inimigos filósofos, criando para eles e para si um plano de imanência, um deserto onde suas tribos podem se encontrar e se confrontar, cruzarem-se por estranhamentos.

Cada filósofo retomado por Gilles Deleuze é lançado num movimento de construção da obra que não cessou, seja com a morte do filósofo, seja com a publicação da obra. Desse modo, desmancham-se, formando linhas de fuga, as propriedades de saber filosófico como determinações de poder estabelecido sobre a produção dos conceitos. Deleuze é um incansável trabalhador que investe os movimentos de estilização conceitual, pela perturbação e fragmentação interna do gênero filosófico.

\section{O PROBLEMA DO GÊNERO FILOSÓFICO DE TRABALHO}

"Tínhamos muita vontade de fazer filosofia, não nos perguntávamos o que ela era, salvo por exercício de estilo; não tínhamos atingido este ponto de nãoestilo em que se pode dizer enfim: mas o que é isso que fiz toda a minha vida?" (DELEUZE; GUATTARI, 1997, p. 9). Esse não-estilo não é o oposto ou a negação do estilo que desenvolve incessantemente Deleuze, é a dimensão genérica da atividade filosófica, tal como Clot $(2006 ; 2010 b)$ a define sempre em relação com os processos de estilização na atividade.

O que é a filosofia? (DELEUZE; GUATTARI, 1997) é uma obra que privilegia o problema do gênero filosófico e tem por objetivo traçar os limites da filosofia em relação a outros domínios da produção social: a arte e a ciência, especificamente. Deleuze sempre trabalhou nessas fronteiras, mas como ele mesmo disse, sempre "por exercício de estilo". Essas fronteiras funcionam e se marcam através das passagens e dos limiares de um gênero em relação a outro, nas suas múltiplas intercessões, perturbações e arranjos, nas estilizações que lhes criam zonas caosmóticas de criação. Essas estilizações sempre foram privilegiadas nos diversos trabalhos de Deleuze, preocupado com o problema da criação, da invenção, da produção. Em $O$ que é a filosofia?, o problema da dimensão genérica da atividade filosófica assume a dianteira, não pelo abandono da dimensão estilística da atividade, mas pela preocupação com sua consistência como uma dimensão intrínseca à atividade ligada a um plano de produção situado. Desse modo, De- 
leuze cuida para que a dimensão genérica não seja confundida com a história da filosofia, nem com as prescrições e tarefas que se tomaram na organização do trabalho filosófico de modo a atrapalhar a produção conceitual.

Essa consideração privilegiada da dimensão genérica do trabalho filosófico como um plano de produção, como recursos e normatizações problemáticas para inventar conceitos, é o assentamento da filosofia como um sistema de variações conceituais cujo desenvolvimento é marcado pelo trabalho de Deleuze, analista, clínico e estilista da atividade filosófica. Trata-se do movimento "em que todas as peças da máquina se combinam para enviar ao porvir um traço que atravesse eras" (DELEUZE; GUATTARI, 1997, p. 9). Deleuze sempre lutou, em suas obras, por afirmar a qualidade, os valores em jogo, do trabalho do filósofo para o fortalecimento do seu ofício. Nessa batalha, afirmam-se os planos distintos e autônomos de produção - filosofia, arte, ciência, etc. - no mesmo movimento em que se sustenta a crucialidade de seus atravessamentos para se desenvolverem mutuamente, como disposições para a criação em seus campos próprios. Pode-se, a partir de Deleuze \& Guattari (1997) e Clot (2006; 2010b), definir a filosofia pela instauração de um plano de imanência como um gênero de ofício próprio, distinto dos gêneros científicos e artísticos, constituídos por plano de referência e plano de composição, respectivamente. Trata-se, para Deleuze, com isso, de diferenciar os gêneros de atividade desde seus planos situados de produção coletiva.

"A filosofia é um construtivismo, e o construtivismo tem dois aspectos complementares, que diferem em natureza: criar conceitos e traçar um plano. [...] É necessário a elasticidade do conceito, mas também a fluidez do meio" (DELEUZE; GUATTARI, 1997, p. 51). Poderíamos dizer, desenvolvendo as considerações de Deleuze, que a criação de conceitos é a dimensão estilística e a sustentação de um plano de consistência é a dimensão genérica da atividade filosófica. A estilização, as intercessões com outros domínios do pensamento, é agora problema para Deleuze desde uma perspectiva que procura definir a multiplicidade própria ao trabalho filosófico. Mesmo quando se trata de se preocupar com a dimensão genérica da atividade filosófica de modo direto, Deleuze afirma, pelo seu trabalho, que isso só é possível por meio da estilização, da criação.

É no momento em que é perturbado que o gênero é visto [...] impulsionando o gênero em suas limitações, brincando com ele, [...] sobre as fragmentações internas ao gênero, sobre a heterogeneidade que marca a emergência das variantes. [...] Portanto, nesse contexto o estilo participa da renovação do gênero, o qual, no limite, nunca se pode dar por acabado. Ele vive, mais ou menos intensamente de resto, das contribuições estilísticas que o reavaliam constantemente e lhe dão sua dinâmica (CLOT, 2006, p. 40)

Nas intercessões, Deleuze extrai as singularidades dos trabalhos de artistas e cientistas, principalmente, por lhes criar um meio de conversação, uma via estrangeira, imprevista, no campo da filosofia, pela qual esses artistas e cientistas podem continuar a produzir, duplicando suas composições em outro meio de 
trabalho, o do filósofo. Essa intercessão só é possível pelas bordas da atividade, por seus limites, por levar adiante os processos de criação em hibridizações de seus fluxos em outros campos. É pelo próprio processo de criação no campo da filosofia, sem abandoná-lo, mas habitando seus limites, que Deleuze pode permitir que um trabalho alheio ao seu em termos de gênero de atividade possa desenvolver suas pulsações de invenção, expandindo e multiplicando seus meios de trabalho por incursões estrangeiras, bárbaras.

\section{A ATIVIDAde DOCENTE COMO INTERCESSORA À ATIVIDAde FILOSÓFICA}

A obra de Gilles Deleuze é professoral, pedagógica. É inegável sua atitude de professor, sua postura como professor, profissão a qual se dedicou durante grande parte da vida, em intercessão com o trabalho filosófico. A atividade docente de Deleuze se cruza com a atividade de construção dos conceitos e marca seus escritos. A presença, entre seus alunos, de artistas, cientistas, estrangeiros, psicanalistas, dentre outros, impregna seu processo de produção conceitual. A imaginar um filosofo isolado em sua sala de trabalho, em casa, ou em qualquer outro lugar, todos os dias, tirando conceitos do si mesmo, do mundo das ideias, ou qualquer outra transcendência, eis certo equívoco. A solidão de Gilles Deleuze é povoada pelos encontros que faz, encontros com pessoas, problemas, situações, seja por meio da aula, seja por meio de outras obras.

Ele atribui grande importância à aula de terça-feira - o essencial de sua semana gira em torno da preparação dela. [...] [Pierre Chevalier diz: "]desde o domingo de manhã, às vezes desde sábado. A aula era muito amadurecida durante três dias e antes de ministrá-la era como uma preparação física, como antes de uma corrida". Quando chega então na terça-feira de manhã, ele de fato não mais necessita da pequena ficha com anotações que tem na mão, porque sabe sua aula de cor. Contudo, dá a impressão de um pensamento prestes a se expressar, pura improvisação e elaboração mental em harmonia com seu público (DOSSE, 2010, p. 291).

Tal sensação de novidade é efeito de um gênero de atividade, a docência, bastante sedimentado, firmado, consistente, agregando uma diversidade de elementos em apoio para os saltos, as estilizações, que se promovem pela aula. Paradoxalmente, é a consistência do gênero docente que lhe permite movimentos, deslocamentos, derivas e rearranjos num trabalho em estilização. Por meio dessa longa preparação, Deleuze pode encontrar seus alunos e conversar com eles, pensar junto com eles, produzindo desvios de pensamento aqui e acolá. Não se trata, absolutamente, em seu trabalho, de transmitir conceitos, mas de dispô-los e experimentá-los, construindo-os com seus alunos novamente.

Os escritos de Deleuze, seus livros e artigos, vários e vários, funcionam junto com suas aulas. Há uma interferência mútua entre a atividade de docência e a escrita filosófica em Deleuze. Os encontros com os alunos, suas interferências durante o ensino, as questões que colocam, as modulações que incitam, os 
mundos que vivem, vão compor os afetos durante a aula que constitui o solo da oficina de conceitos que Deleuze inventa para si. E os conceitos, por sua vez, permitem construir meios de conversação, instrumentos de invenção de mundos e problemas a viver, de interferências nos percursos do pensamento, entre alunos e professor. Os escritos de Deleuze são antecedentes e efeitos de sua preparação de aulas e das incisões crucias que seus alunos lhe proporcionam. Tal vitalidade na produção conceitual é efeito dos bons encontros (ESPINOSA, 1983; DELEUZE, 2002), os quais Deleuze se esforça incansavelmente por promover.

[...] 'Não sei bem do que se trata, mas gosto bastante'. Tinhase de fato a impressão de que ele se dirigia a todo mundo". [... "Havia uma senhora idosa que vinha a todas as aulas, e fazia um certo frio nesse dia. Nos intervalos, a maioria dos estudantes saía para fumar, e eu fiquei. Dirijo-me a essa mulher para lhe perguntar alguma coisa, pois ela nunca faltava a uma aula. Ela me responde: 'O senhor sabe, ele me ajuda a viver'. Existe de fato algo nesse pensamento que ajuda as pessoas a viver" (DOSSE, 2010, p. 294).

\section{Filosofia PrÁtica como trabalHo EM PROBlemas CONCRETOS: DROGA,}

\section{LITERATURA, LOUCURA}

É a vida como luta e criação que Deleuze afirma em oposição à morte, definida como interrupção da processualidade, do construtivismo. Quando, entretanto, fala em caos para opor à construção (DELEUZE; GUATTARI, 1997), não cai em mútua exclusão; pelo contrário, acompanha seu comparsa ${ }^{12}$ Guattari (1992) com a sustentação de paradoxos, pelo combate no plano das multiplicidades, que precisam ser trabalhadas, sempre ameaçadas pelo caos, para ganharem consistência. Todo o problema de Deleuze acerca das multiplicidades gira em torno da atividade com a qual lhes seja possível compor, dar-lhes consistência, numa perseveração da existência - conatus (ESPINOSA, 1983).

Eis porque o problema da atividade, do trabalho, é tão crucial no percurso de Gilles Deleuze. Do contrário, caímos no caos sem consistência de experimentações sem que se criem suportes para os processos criativos. Só a atividade produtora de mundos pode sustentar os tensionamentos do caos, impedindo-lhes configurar nulidades. Nosso filósofo tem como preocupação fundamental, portanto, o trabalho, definido como atividade produtiva desejante e social.

Em $O$ anti-édipo, o foco fundamental de Deleuze \& Guattari (2010) é desenvolver a noção de trabalho como invenção, criação, e a noção de desejo como produção, funcionamento, em vez apelar às categorias do pensamento representacional. Esse livro é uma máquina de análise que privilegia os campos de atividade de Félix Guattari, a militância política marxista e a psicanálise freudiana, mas também se configura claramente como um trabalho filosófico, no âmbito do ofício deleuzeano. Trata-se de um entrecruzamento por diversos ofícios. Paradoxalmente, ao se dispor às análises dos meios de atividade do amigo, Deleuze eleva a potência de produção conceitual em seu trabalho a um ponto limite para o qual 
todo seu trabalho anterior, relativo à história da filosofia e ao estabelecimento de teses, pode ser vislumbrado, desde então, como uma longa preparação para um fecundo encontro em que se inventam conceitos em experimentações múltiplas.

Tal desenvolvimento prossegue em Mil platôs (DELEUZE; GUATTARI, 1980), obra em que expandem consideravelmente as intercessões com diversas outras modalidades de trabalho, sustentadas pelo conceito e prática do agenciamento, ou seja, conexões e disjunções de elementos os mais distintos pelas incongruências, produzindo tensionamentos multiplicizantes. Capitalismo e esquizofrenia (DELEUZE; GUATTARI, 1980; 2010) é, portanto, um longo trabalho cuja preocupação básica são as relações entre trabalho e desejo, atividade e criação. Encontramos o mesmo foco de preocupação com o trabalho, por parte de Deleuze, ao considerar as relações do homem com o álcool, implicando-se nessa análise.

Beber, se drogar, tudo isso parece tornar quase possível algo forte demais, mesmo se se deve pagar depois, sabe-se, mas em todo caso, está ligado a isto, trabalhar, trabalhar. E é evidente que quando tudo se inverte, e que beber impede de trabalhar, e a droga se torna uma maneira de não trabalhar, é o perigo absoluto, não tem mais interesse, e, ao mesmo tempo, percebe-se, cada vez mais, que quando se pensava que o álcool ou a droga eram necessários, eles não são necessários. Talvez se deva passar por isso, para perceber que tudo o que se pensou fazer graças a eles podia-se fazer sem eles. Admiro muito a maneira como [Henri] Michaux diz: agora, tornou-se, tudo isso é... ele pára. Eu tenho menos mérito, porque parei de beber por razões de respiração, de saúde, etc., mas é evidente que se deve parar ou se privar disso. A única justificação possível é se isso ajuda o trabalho. Mesmo se se deve pagar fisicamente depois. Quanto mais se avança, mais a gente diz a si mesmo que não ajuda o trabalho... (DELEUZE; PARNET, 2001)

As relações com o álcool, a droga, a arte, o sexo, a família, os amigos, sempre remetem, afinal, ao trabalho, à produção desejante e social. Deleuze tem, portanto, como preocupação fundamental a atividade, ainda que não se preocupe em conceituá-la. Não se trata do trabalho definido como sofrimento no sentido de algo ruim, como exploração, como condição humana antagônica a alguma condição divina de liberdade, ainda que a problemática da produção desejante e social envolvam essas dimensões de impasse e bloqueio dos processos de criação que são a base do trabalho. Inclusive a relação com o álcool, o agenciamento com o álcool, Deleuze a apreende de tal modo que toma como questão crucial o problema da atividade produtiva, do trabalho. Poderíamos dizer que, como para Yves Clot (2006), também para Gilles Deleuze, a seu modo, o trabalho é a atividade transpessoal por excelência, o plano em que se cruzam todas as dimensões da vida em produção desejante. 
A abordagem da literatura por Deleuze segue sempre essa orientação paradoxal: como pensar os problemas do trabalho nessa linha limite com a loucura, com a arte, com os fluxos desejantes disparatados. Bartleby, ou a fórmula que não cessa de desconcertar a organização do trabalho no escritório de advocacia em que se emprega, encanta Deleuze (1997). Essa fascinação pelas figuras esquizofrênicas ${ }^{13}$ não é exatamente derivada da companhia de "doentes mentais". Guattari já o indica: "Gilles me diz nessa ocasião: "Como você pode suportar os esquizos?'. Ele não conseguia suportar a visão dos loucos” (DOSSE, 2010, p. 17). Tal situação, que poderia vir a ser a contradição na qual Deleuze se encontraria paralisado em seu trabalho, instala um paradoxo onde o filósofo pode trabalhar.

O que interessa ao nosso filósofo é o esquizofrênico como potência de criação de mundos, sem restringi-lo ao trapo autista produzido pelas artimanhas do poder como doente mental; sem, contudo, negar que seja esse o perigo de captura do processo em redes de poder. Essa posição é crucial para entendermos o paradoxo em que se sustenta a relação de Deleuze com os esquizofrênicos. Tal encontro é, sobretudo, desenvolvido pela preocupação com o trabalho em sua dimensão fundamental: a produção desejante e social. A abordagem da esquizofrenia, possibilitada pela literatura e, posteriormente, pelo encontro com Guattari, que trabalha numa clínica que abriga esquizofrênicos, é um meio percorrido por Deleuze para não sucumbir à contradição, ao impasse, com os esquizos, no seu trabalho de criação conceitual.

Os esquizofrênicos problematizam insistentemente, e por vezes, sistematicamente, os sentidos e os meios de trabalho. O que é produzir? É criar objetos úteis? Úteis a que? É criar coisas que funcionem? Que funcionamentos? O transtorno que Bartleby promove no seu meio de trabalho não é a negação do trabalho, nem sua superação por um mundo originário ou utopia futura sem trabalho, mas a própria fonte de desenvolvimento do trabalho. O trabalho só insiste e consiste por essa potência esquizofrênica que não cessa de lhe perturbar os sentidos e os funcionamentos, convocando à invenção de outros, problematizando os fins do trabalho como a organização os demarca, inventando relações outras para o que trabalho não se estagne e cesse no vazio de sentido, na falta de desejo como buraco a se consumir. A esquizofrenia é o limite do trabalho, sua possibilidade de criar territórios a viver. Encontramos a esquizofrenia como base e como limite do trabalho, no contexto capitalista (DELEUZE; GUATTARI, 2010).

Por essa via, a loucura não é negação ou impedimento fatal da relação com o trabalho e com o real, como se tem perspectivado nas clínicas do trabalho, de modo hegemônico, marcadas ainda pela primazia da identificação, reconhecimento e individualização como eixos de sustentação do trabalho. A loucura, a esquizofrenia, é o paradoxo dos sentidos, usos e funcionamentos que o trabalho arranja e desarranja a todo instante para produzir. Tal perspectiva a que Deleuze nos convoca a desenvolver, pelo seu trabalho no meio filosófico, instala as atuais abordagens clínicas do trabalho em um limite fecundo, construindo um horizonte de problematização que nos parece bastante promissor para as abordagens das atividades produtivas. Desmanchar o impasse com os improdutivos, os esquizo- 
frênicos, pela sustentação dos paradoxos do trabalho é o convite, sem remetente e destinatário assinalados, que Gilles Deleuze deixa aos psicólogos - especialmente, aos psicólogos do trabalho - nos dias atuais.

\section{Notas}

Em clínica da atividade, procura-se definir a função psicológica do trabalho (CLOT, 2006), colocando-se o problema de como o trabalho vem a ser crucial à subjetivação humana. Abordado como produção social que se inscreve na história, o trabalho não é confundido com as categorias pelas quais é reconhecido na atualidade, sobretudo a relação empregatícia - o que, de maneira alguma, implica desconsiderar tal situação. A questão da atividade, tal como operada por Canguilhem (2009) e Vygotski (apud CLOT, 2006; 2010b), será crucial nessa definição. "O que constitui a função psicológica do trabalho é, paradoxalmente, ser um objeto estranho a nossas necessidades imediatas que não se harmoniza de modo direto com nossa atividade" (CLOT, 2006, p. 70). Dessa maneira, o trabalho possibilita ao sujeito constituir-se, paradoxalmente, por um "sair de si" pela "capacidade de estabelecer engajamentos" (CLOT, 2006, p. 68.72). Por isso, dentre os vários meios de atividade, o trabalho se configura para o homem como decisivo às formações sociais, "um gênero de situação do qual uma sociedade dificilmente pode abstrair-se sem comprometer sua perenidade" (CLOT, 2006, p. 69).

O conceito de estilo é tomado por Yves Clot $(2006 ; 2010 b)$ de Mikhail Bakhtin e se refere à criação situada num meio coletivo de produção que não se pode definir por generalização totalizante nem por individualização homogeneizante. Para Deleuze (2003, p. 345-347, tradução nossa, grifo do autor) "[...] o estilo consiste em colocar as variáveis em variação. Cada estilo é uma tal colocação em variação, que é preciso seguir e definir concretamente. [...] As variáveis percorrem zonas de variação finitas ou infinitas, contínuas ou descontínuas, que constituem o estilo como modulação [...]. Cada variável passa e repassa por posições diversas sobre uma linha de modulação particular: daí o estilo que caminha sempre por repetição-progressão. [...] Da mesma forma, quando se diz que o estilo é como uma língua estrangeira não se trata de uma língua diferente da que falamos, trata-se de uma língua estrangeira na língua que falamos.". Deleuze e Clot, quanto ao problema do estilo, podem se encontrar nas diversas apropriações que fazem de Bakhtin, mas, sobretudo, em Marcel Proust (DELEUZE, 2010; CLOT, 2011). Para uma discussão do conceito de estilo em clínica da atividade pela intercessão com a filosofia de Gilles Deleuze, pode-se consultar Barros, Pinheiro e Zamboni (2010).

3 “O essencial são os intercessores. A criação são os intercessores. Sem eles não há obra. [...] Eu preciso de meus intercessores para me exprimir, e eles jamais se exprimiriam sem mim: sempre se trabalha em vários, mesmo quando isso não se vê." (DELEUZE, 1992, p. 156).

4 "Os nomes, os seres e as coisas estão abarrotados de um conteúdo que os faz explodir; assiste-se, então, não só a uma espécie de explosão dos continentes pelos conteúdos, mas à explosão dos próprios conteúdos que, desdobrados, explicados, não formam uma figura única, mas verdades heterogêneas em fragmentos que lutam muito mais entre si do que se conciliam." (DELEUZE, 2010, p. 115). Nesse sentido, o estatuto da autoria em Deleuze (DELEUZE; GUATTARI, 1980) se coloca como problemático, já que não caberia tanto separar o autor, sua obra e o mundo no qual se inserem, mas importa o que se inventa pelo que se produz.

Deleuze (2005) desenvolve o problema do fora, da exterioridade, a partir de Foucault. "[...] o lado de fora diz respeito à força: se a força está sempre em relação com outras forças, as forças remetem necessariamente a um lado de fora irredutível, que não tem mais sequer forma, feito de distâncias indecomponíveis através das quais uma força age sobre outra ou recebe a ação de outra." (DELEUZE, 2005, p. 93). Aí podemos encontrar claramente a retomada da abordagem de Nietzsche por Deleuze (1976) para acompanhar o pensamento de Michel Foucault - embora Foucault pudesse ver-se em algum momento "exasperado de ver a obra de Nietzsche ligada à leitura feita por Deleuze" (DOSSE, 2010, p. 254). Trata-se do roubo deleuzeano, ou seja, um princípio procedimental, sempre variante no percurso, pelo qual os conceitos podem se desenvolver. O roubo não é o plágio do trapaceiro, mas a criação do traidor (DELEUZE; PARNET, 1998), de maneira que, ao não buscar fidelidade ou verdade a estabelecer pelo trabalho filosófico de Foucault, Deleuze o faz variar e estranhar-se a si mesmo.

${ }^{6}$ Ao definir a subjetivação como dobra, curvatura das forças do fora, Deleuze com Foucault (2005) explicita a relação dos processos de subjetivação com as singularidades, com as variações 
intensivas, que perturbam radicalmente a noção de um sujeito absoluto, constituído como substância homogeneizante. O pensamento, que constitui o sujeito, seria assim completamente reconfigurado por Foucault. "A idéia fundamental de Foucault é a de uma dimensão da subjetividade que deriva do poder e do saber, mas que não depende deles. [...] Demais, em função do poder como problema, pensar é emitir singularidades, é lançar os dados. O que o lance de dados exprime é que pensar vem sempre de fora. [...] E é isto a linha de fora: a linha que não pára de reencadear as extrações, feitas ao acaso, em mistos de aleatório e de dependência. Pensar assume aqui, então, novas figuras: obter singularidades; reencadear as extrações, os sorteios; e inventar, a cada vez, as séries que vão da vizinhança de uma singularidade à vizinhança de outra. Existem singularidades de todos os tipos: singularidades de poder, apanhadas em relações de forças; singularidades de resistência, que preparam as mutações; e mesmo singularidades selvagens, que ficam suspensas no lado de fora sem entrar em relações nem se deixar integrar..." (DELEUZE, 2005, p. 109-125). ${ }^{7}$ Em clínica da atividade, propõe-se a abordagem das situações de trabalho, de maneira a acompanhar as transformações do trabalho. Estas transformações encontram sua força instituinte, segundo Clot (2010b), na atividade coletiva dos trabalhadores. Portanto, seria preciso não partir do instituído das organizações do trabalho, mas da ação concreta dos sujeitos que, ao transformarem suas situações, possibilitam conhecê-las (CLOT, 2006; 2010b). Dessa maneira, inverte-se a hegemônica estratégia do saber segundo a qual é preciso primeiro conhecer, investigar a realidade dada, para poder agir, modificando-a de maneira controlada. A realidade, em clínica da atividade, é a própria transformação do real. Isto está profundamente conectado à perspectiva deleuzeana em filosofia ao afirmar que é preciso experimentar em vez de interpretar (DELEUZE; GUATTARI, 1980; 2010).

${ }^{8}$ Deleuze e Guattari (1980) discutem o conceito de máquina de guerra pensando a exterioridade das formações estatais, ou seja, os processos instituintes pelos quais se pode transformar radicalmente a organização social estabelecida, instituída.

${ }^{9}$ Máquinas desejantes é um conceito inventado por Deleuze e Guattari (2010) a partir de seus encontro e trabalho juntos. Pretende-se com ele desenvolver a radicalidade da relação do desejo com o social pelo problema da produção. Ou seja, ao não tomar nem o desejo nem o social como transcendentes às relações, coloca-se a questão de suas produções, da sociedade e do desejo, como indissociáveis.

${ }^{10}$ Podemos destacar, dentre essas estranhas alianças para as classificações hegemônicas, a que se faz entre o empirismo de David Hume (DELEUZE, 2001) e o racionalismo de Baruch de Espinosa (DELEUZE, 2002), normalmente associados a escolas opostas, mas que, pela filosofia da diferença de Deleuze, conversam indiretamente. Há também o caso de Friedrich Nietzsche, cuja associação ao existencialismo, sobretudo em Martin Heidegger, torna-se extremamente problemática diante da perspectiva de Deleuze (1976) em diálogo com Nietzsche. Pode-se, ainda, citar o tema da dobra que é crucial às discussões de Deleuze sobre Michel Foucault (DELEUZE, 2005) e Gottfried Leibniz (DELEUZE, 2009). É preciso, contudo, notar que não se tratam de misturas indiferenciantes, que poriam em ordem toda essa horda de filósofos, mas de sustentarlhes as controvérsias num meio comum que é a obra de Gilles Deleuze.

11 "Os conceitos são como as vagas múltiplas que se erguem e que se abaixam, mas o plano de imanência é a vaga única que os enrola e os desenrola.” (DELEUZE; GUATTARI, 1997, p. 51). Embora, em $O$ que é a filosofia?, destaque-se a distinção do plano de imanência de outros planos de produção - especificamente, das ciências e das artes -, é preciso lembrar que Deleuze não cessa de promover intercessões entre esses diversos planos de produção em suas obras. "O que me interessa são as relações entre as artes, a ciência e a filosofia. Não há nenhum privilégio de uma destas disciplinas em relação a outra. Cada uma delas é criadora. O verdadeiro objeto da ciência é criar funções, o verdadeiro objeto da arte é criar agregados sensíveis e o objeto da filosofia, criar conceitos. A partir daí, se nos damos essas grandes rubricas, por mais sumárias que sejam - função, agregado, conceito -, podemos formular a questão dos ecos e das ressonâncias entre elas. Como é possível, sobre linhas completamente diferentes, com ritmos e movimentos de produção inteiramente diversos - como é possível que um conceito, um agregado e uma função se encontrem?" (DELEUZE, 1992, p. 154).

${ }_{12}$ "Meu encontro com Félix Guattari mudou muitas coisas. [...] Eu tentei em meus livros precedentes descrever um certo exercício do pensamento; mas descrevê-lo ainda não era exercer o pensamento daquele modo. [...] Eis que, com Félix, tudo isso se tornava possível, até mesmo se fracassássemos. Eramos apenas dois, mas o que contava para nós era menos trabalhar juntos do que esse fato estranho de trabalhar entre os dois." (DELEUZE; PARNET, 1998, p. 24-25). 
Quando tratamos Bartebly como uma figura esquizofrênica em torno da qual Deleuze trabalha, é preciso aqui deixar claro que não se trata da doença mental tal como é classificada pela psiquiatria moderna. Deleuze inventa um conceito de esquizofrenia, como notou Pereira (2009), e é à experiência que possibilita forjar este conceito que nos remetemos.

\section{REFERÊNCIAS}

AMADOR, F. S. Entre prisões da imagem, imagens da prisão: um dispositivo tecno-poético para uma clínica do trabalho. 2009. $230 \mathrm{f}$. Tese (Doutorado em Informática na Educação) - Programa de Pós-Graduação em Informática na Educação, Universidade Federal do Rio Grande do Sul, Porto Alegre, 2009.

BARROS, M. E. B. de; PINHEIRO, Diego Arthur Lima; ZAMBONI, Jésio. Psicologia do estilo: nas bordas da atividade. Arquivos Brasileiros de Psicologia, Rio de Janeiro, v. 62, n. 1, p. 62-71, jan./abr. 2010.

CANGUILHEM, G. O normal e o patológico. Rio de Janeiro: Forense Universitária, 2009.

CLOT, Y. A função psicológica do trabalho. Petrópolis: Vozes, 2006.

CLOT, Y. A psicologia do trabalho na França e a perspectiva da clínica da atividade. Fractal: Revista de Psicologia, Niterói, v. 22, n. 1, p. 207-234, jan./ abr. 2010a.

CLOT, Y. Trabalho e poder de agir. Belo Horizonte: Fabrefactum, $2010 \mathrm{~b}$.

CLOT, Y. Prefácio. In: ROSEMBERG, Dulcinéa Sarmento; RONCHI FILHO, Jair; BARROS, Maria Elizabeth Barros de. Trabalho docente e poder de agir: clínica da atividade, devires e análises. Vitória: EDUFES, 2011. p. 11-14.

DELEUZE, G. Nietzsche e a Filosofia. Rio de Janeiro: Ed. Rio, 1976.

DELEUZE, G. Conversações: 1972-1990. São Paulo: Ed. 34, 1992.

DELEUZE, G. Crítica e clínica. São Paulo: Ed. 34, 1997.

DELEUZE, G. Empirismo e subjetividade: ensaio sobre a natureza humana segundo Hume. São Paulo: Ed. 34, 2001.

DELEUZE, G. Espinosa: filosofia prática. São Paulo: Escuta, 2002.

DELEUZE, G. Préface: une nouvelle stylistique. In: . Deux régimes de fous: textes et entretiens. Paris: Minuit, 2003. p. 343-347.

DELEUZE, G. Foucault. São Paulo: Brasiliense, 2005. 
DELEUZE, G. A Ilha Deserta: e outros textos. Textos e entrevistas (1953-1974). São Paulo: Iluminuras, 2006a.

DELEUZE, G. Diferença e repetição. Rio de Janeiro: Graal, 2006b.

DELEUZE, G. A dobra: Leibniz e o barroco. Campinas: Papirus, 2009.

DELEUZE, G. Proust e os signos. Rio de Janeiro: Forense Universitária, 2010.

DELEUZE, G.; GUATTARI, F. Mille plateaux: Capitalisme et schizophrénie 2. Paris: Minuit, 1980.

DELEUZE, G. O que é a Filosofia?. Rio de Janeiro: Ed. 34, 1997.

DELEUZE, G. O anti-édipo: capitalismo e esquizofrenia 1. São Paulo: Ed. 34, 2010.

DELEUZE, G; PARNET, C. Diálogos. São Paulo: Escuta, 1998.

DELEUZE, G. L'abécédaire. Paris: Montparnasse, 2001.

DOSSE, F. Gilles Deleuze \& Félix Guattari: biografia cruzada. Porto Alegre: Artmed, 2010.

ESPINOSA, B. de. Pensamentos metafísicos; Tratado de correção do intelecto; Ética; Tratado político; Correspondência. São Paulo: Abril Cultural, 1983.

GUATTARI, F. Caosmose: um novo paradigma estético. São Paulo: Ed. 34, 1992.

LOUZADA, A. P. F. Crônicas de um trabalho docente: a invenção como imanente à vida. 2009. 198 f. Tese (Doutorado em Educação) - Programa de PósGraduação em Educação, Universidade Federal do Espírito Santo, Vitória, 2009.

LHUILIER, D. Filiações teóricas das clínicas do trabalho. In: BENDASSOLLI, Pedro Fernando; SOBOLL, Lis Andrea Pereira. (Orgs.). Clínicas do trabalho: novas perspectivas para compreensão do trabalho na atualidade. São Paulo: Atlas, 2011. p. 22-58.

MAIA, M. Â. B. O corpo invisivel do trabalho: cartografia dos processos de trabalho em saúde. 2006. 196 f. Dissertação (Mestrado em Psicologia) - Programa de Pós-Graduação em Psicologia, Universidade Federal Fluminense, Niterói, 2006. 
PEREIRA, J. C. P. Clínica da esquizofrenia: como um filósofo produziu um novo conceito. 2009. 123 f. Dissertação (Mestrado em Psicologia Institucional) - Programa de Pós-Graduação em Psicologia Institucional, Universidade Federal do Espírito Santo, Vitória, 2009.

SCHWARTZ, Y. Ergonomia, filosofia e exterritorialidade. In: DANIELLOU, François. (Org.). A ergonomia em busca de seus princípios: debates epistemológicos. São Paulo: Edgard Blücher, 2004. p. 141-180.

TEIXEIRA, D. V; BARROS, M. E. B. de. Clínica da atividade e cartografia: construindo metodologias de análise do trabalho. Psicologia \& Sociedade, Florianópolis, v. 21, n. 1, p. 81-90, jan./abr. 2009.

Recebido em: 06 de março de 2012 Aceito em: 10 de outubro de 2012 
